\title{
Male germline development in the tammar wallaby, Macropus eugenii
}

\author{
Teruhito Ishihara $^{+} \mathbb{B}$, Oliver W Griffith ${ }^{+} \mathbb{D}$, Gerard A Tarulli®i and Marilyn B Renfree \\ School of BioSciences, The University of Melbourne, Melbourne, Victoria, Australia \\ Correspondence should be addressed to M B Renfree; Email: m.renfree@unimelb.edu.au \\ ${ }^{\dagger}(\mathrm{O}$ W Griffith is now at Department of Biological Sciences, Macquarie University, Sydney, New South Wales, Australia)
}

\begin{abstract}
Male germ cells undergo two consecutive processes - pre-spermatogenesis and spermatogenesis - to generate mature sperm. In eutherian mammals, epigenetic information such as DNA methylation is dynamically reprogrammed during pre-spermatogenesis, before and during mitotic arrest. In mice, by the time germ cells resume mitosis, the majority of DNA methylation is reprogrammed. The tammar wallaby has a similar pattern of germ cell global DNA methylation reprogramming to that of the mouse during early pre-spermatogenesis. However, early male germline development in the tammar or in any marsupial has not been described previously, so it is unknown whether this is a general feature regulating male germline development or a more recent phenomenon in mammalian evolutionary history. To answer this, we examined germ cell nuclear morphology and mitotic arrest during male germline development in the tammar wallaby (Macropus eugenii), a marsupial that diverged from mice and humans around 160 million years ago. Tammar pro-spermatogonia proliferated after birth and entered mitotic arrest after day 30 postpartum (pp). At this time, they began moving towards the periphery of the testis cords and their nuclear size increased. Germ cells increased in number after day $100 \mathrm{pp}$ which is the time that DNA methylation is known to be re-established in the tammar. This is similar to the pattern observed in the mouse, suggesting that resumption of germ cell mitosis and the timing of DNA methylation reprogramming are correlated and conserved across mammals and over long evolutionary timescales.

Reproduction (2021) 161 333-341
\end{abstract}

\section{Introduction}

Male germ cells undergo two sequential developmental processes to generate mature sperm; prespermatogenesis and spermatogenesis. At the beginning of pre-spermatogenesis, pro-spermatogonia, also known as gonocytes, become enclosed in testis cords and enter a period of rapid proliferation (Wartenberg 1978). These proliferating germ cells are known as Mitoticpro-spermatogonia (M-pro-spermatogonia) (McCarrey 2013). Coincident with the entrance into this highly proliferative phase in mice, global DNA demethylation occurs (Hackett et al. 2013, Kawasaki et al. 2014). After this period of rapid proliferation germ cells enter a second phase, the transitional phase. The first step of this phase is mitotic arrest, in which the arrested cells are known as T1-pro-spermatogonia (Western et al. 2008, McCarrey 2013). They retain their capacity to proliferate but are arrested at the G0/G1 stages of the cell cycle (McLaren 2001, Western et al. 2008). T1-prospermatogonia resume mitosis and the daughter cells are known as T2-pro-spermatogonia (McCarrey 2013). The population of T2-pro-spermatogonia gradually increases and a proportion of these cells become the direct precursors of the spermatogonial stem cells that initiate spermatogenesis (Kluin \& Rooij 1981, Culty 2009, McCarrey 2013).

The onset of mitotic arrest and resumption of mitosis are highly correlated with genome-wide DNA methylation dynamics in mice and are important for appropriate genomic imprinting that is critical for successful reproduction. Epigenetic marks such as DNA methylation and histone modifications enable the regulation of gene expression in a cell type-specific manner. Correct programming of epigenetic marks is essential for cell differentiation in eutherian mammals (Arney \& Fisher 2004). In mammalian germ cells, epigenetic marks endow parent-of-origin-specific monoallelic expression of some genes as part of the critical process of genomic imprinting (Bartolomei \& Ferguson-Smith 2011). During gametogenesis, the majority of epigenetic information is reprogrammed to erase existing parental imprints that reset sex-specific imprinting marks in the male and female germ cells (Bartolomei \& Ferguson-Smith 2011, Matsui \& Mochizuki 2014). Reprogramming of the primary modification, DNA methylation, during gametogenesis is well characterised in eutherian mammals. The germline precursors, the primordial germ cells, begin to proliferate and delete DNA methylation programmes during their migration from the epiblast 
to the genital ridge (Wartenberg 1978, McLaren 1992, McCarrey 2013). Female and male germ cells show sexually dimorphic proliferation after entering the gonads when the female germ cells begin meiosis and male germ cells enter a transitional phase with cell cycle arrest (Kocer et al. 2009). Loss of DNA methylation is known to induce activation of meiosis-related factors in female mouse germ cells (Yamaguchi et al. 2012, Hargan-Calvopina et al. 2016), so the wave of DNA demethylation also regulates the progress of oogenesis in mouse. Loss of DNA methylation is also known to upregulate a male germline differentiation initiator, Nanos2, though upregulation of Nanos2 is not required for the initiation of the transitional phase (Suzuki \& Saga 2008, Hargan-Calvopina et al. 2016, Pui \& Saga 2018). The wave of DNA demethylation is also likely to be involved in male germline development, linking the process of DNA methylation reprogramming and germline development.

Whether this is a general feature of all mammals or unique to eutherians is currently unclear. To identify if this pattern of germ cell reprogramming has been conserved in the male germline development of therian mammals (marsupials and eutherians) for over 160 million years ago (MYA) (Luo et al. 2011), we used a marsupial, the tammar wallaby (Macropus eugenii), whose endocrine and reproductive biology has been extensively characterised. Since early male germline development in the tammar has not been described previously, here we investigate the timing of mitotic arrest after birth during the period of epigenetic reprogramming to correlate male germline development with existing DNA methylation data for this species. We report that early tammar germ cell development has similar features to mouse germ cell development, demonstrating conserved elements of germline development over long mammalian evolutionary timescales.

\section{Materials and methods}

\section{Animals}

Tammar wallabies (M. eugenii), of Kangaroo Island origin, were held in open grassy yards in our breeding colony at the University of Melbourne. Food was supplemented with lucerne cubes. Age of pouch young was estimated from head length growth curves (Poole et al. 1991). Pouch young (PY) over $5 \mathrm{~g}$ were anaesthetised with $5 \mathrm{mg} / \mathrm{kg}$ Zoletil (tiletamine/ zolazepam:100 mg/mL) (Virbac, Australia) i.m. before killing by decapitation. Testes were dissected and fixed in $4 \%(\mathrm{w} / \mathrm{v})$ paraformaldehyde (PFA) in PBS $(140 \mathrm{mM} \mathrm{NaCl}, 2.7 \mathrm{mM}$ $\mathrm{KCl}, 10 \mathrm{mM} \mathrm{Na} \mathrm{HPO}_{4}, 1.8 \mathrm{mM} \mathrm{KH} \mathrm{PO}_{4}, \mathrm{pH}$ 7.4), washed and stored in $100 \%$ methanol before histological analysis. All animal experiments were approved by the University of Melbourne Animal Experimental Ethics Committees and followed the Australian National Health and Medical Research Council (2013) guidelines.

\section{Histology}

PFA fixed samples were washed in $1 \times$ PBS and rehydrated through an ethanol series before being embedded in paraffin. Embedded samples were serially sectioned at $5 \mu \mathrm{m}$ and mounted on polylysine coated slides (ThermoFisher Scientific). Sections were de-waxed, rehydrated through an ethanol-PBS series, incubated with haematoxylin for 5 min. soaked in tap water, incubated in acid alcohol and Scott's $\mathrm{H}_{2} \mathrm{O}$ and stained with eosin for $20 \mathrm{~s}$ then mounted with mounting media. Images were collected on an Olympus DP70 Microscope Digital Camera System (Olympus).

\section{Immunofluorescence staining}

Sections were de-waxed, rehydrated through decreasing concentrations of ethanol, and then incubated in $0.1 \%(\mathrm{v} / \mathrm{v})$ Triton X-100 in $1 \times$ PBS (PBST) for 15 min at room temperature to permeabilise the tissue. Slides were boiled in Tris-EDTA $(\mathrm{pH} 8.0)$ for $20 \mathrm{~min}$. For phospho-H3S10 (P-HH3) and SOX9 co-staining, the sections were treated with $0.3 \%(\mathrm{w} / \mathrm{v})$ Sudan black in $70 \%(\mathrm{v} / \mathrm{v}) \mathrm{EtOH}$ solution for $15 \mathrm{~min}$ to reduce autofluorescent background. The Sudan black treated sections were washed by $70 \%(\mathrm{v} / \mathrm{v}) \mathrm{EtOH}$ and $1 \times \mathrm{PBS}$ before blocking. Thereafter, the sections were incubated for $1 \mathrm{~h}$ with $10 \%$ $(w / v)$ goat serum diluted in $1 \times$ PBS. After blocking, sections were incubated with primary antibody solution at $4^{\circ} \mathrm{C}$ for 16 h (Supplementary Table 1, see section on supplementary materials given at the end of this article). The following day, sections were washed three times with PBS and then incubated with fluorescent secondary antibodies for $1 \mathrm{~h}$ (Supplementary Table 1). Sections were washed three times with $1 \times$ PBS again and then incubated for $10 \mathrm{~min}$ with DAPI (Sigma-Aldrich). DAPI treated sections were mounted with fluorescence mounting solution. The controls for all treatments were no primary antibody and IgG isotype control antibodies. Images were collected on a Nikon A1R Confocal Laser Microscope System (Nikon).

\section{Counting pro-spermatogonia and testis cord sections}

To count the numbers of germ cells per area, a systematic random sampling of counting area was taken through the testis by the following method. Images were collected on the Olympus DP70 Microscope Digital Camera System. They were cropped as a square figure and overlapped with $15 \times 15$ gridline using the Fiji programme (2.0.0-rc-69/1.52i) (https:// fiji.sc). The first section to be counted was allocated by rolling a dice and a total of 10 sections were investigated to count germ cell number, equally spaced through the testis from the first section. Since testes at around day 10 postpartum (pp) were too small to fit the method, whole testis cords and germ cells within sections were investigated. The sums of counted numbers of germ cells were normalised to the total area of counted frames $\left(\mathrm{mm}^{2}\right)$. Differences in the normalised counted number between grouped ages and each animal were analysed by ANOVA before Tukey Kramer's HSD test and linear regression analysis using R (https://www.r-project.org), respectively. 


\section{Cytological analysis}

Nuclear sizes of germ cells were measured by the Fiji programme, and the data were grouped from $5 \mu \mathrm{m}^{2}$ to $110 \mu \mathrm{m}^{2}$ at $5 \mu \mathrm{m}^{2}$ intervals. In each animal, the total number of germ cells in each categorised nuclear size was normalised to the total numbers of counted germ cells of each animal. Averages of each normalised value among grouped ages were calculated to estimate the changes in populations of the differentiating germline. Median values of nuclear size within each animal were calculated. Changes in the median values between ages were analysed by linear regression analysis with $\mathrm{R}$.

\section{Frequencies of germ cells within testis cords}

Areas of each testis cord were measured as described above by the Fiji programme, and the total numbers of germ cells within each testis cord were counted on the basis of the systematically counting method (Supplementary Table 2). The counted numbers were normalised to the size of each testis cord section (Supplementary Fig. 1). We took a mean value of the normalised number of germ cells as 'Germ cell frequency' to compare between grouped ages and among animals. The differences in germ cell frequency were analysed by ANOVA before Tukey Kramer's HSD test and linear regression analysis using $R$, respectively.

\section{Proliferation analysis}

Proliferating germ cells in the developing testes were analysed by IF with a proliferation marker $(\mathrm{P}-\mathrm{HH} 3)$ specific antibody and a Sertoli cell marker SOX9-specific antibody, to determine the identity of proliferating cells within developing cords. The anti-P-HH3 antibody can detect mitotic cells specifically (Fukushima et al. 2009). More than 10 sections were prepared from each animal and intervals between sections were more than $10 \mu \mathrm{m}$ depending on animal ages. Sections with $\mathrm{P}-\mathrm{HH} 3$ positive cells were used for further quantitation. Quantitation was performed on $>3$ fields for each animal ( $n=5$ /group). The interstitium was outlined and excluded so that only testis cords were quantified. Total P-HH3-positive cells were determined as well as the proportion of proliferating Sertoli cells, using co-localisation with SOX9 and mean fluorescence intensity measured in Fiji. Proliferating germ cells were determined by lack of the Sertoli cell-specific SOX9 expression. Differences in the ratio of $\mathrm{P}-\mathrm{HH} 3$ positive germ cells were analysed by ANOVA with Tukey's multiple comparisons test using R.

\section{Results}

\section{Germ cells move to the periphery of testis cords during development}

The Sertoli cell marker, SOX9 was detected in cells at the periphery of the testis cords (Fig. 1A). The germ cell marker, DDX4, was detected in the cytoplasm of germ cells, and germ cell localisation was different depending on ages of animals (Fig. 1B). Spermatogonia in the developing testis were large and had pale stained nuclei, while Sertoli cells had darkly stained nuclei (Fig. 1C). At around day $30 \mathrm{pp}$, germ cells were predominantly located in the centre of the testis cords. At day 50 pp, a greater proportion of germ cells were located at the periphery. After day 100 pp, most germ cells were located at the periphery of the testis cords. At around day $70 \mathrm{pp}$, germ cell nuclear size was approximately 1.69fold (59\%) larger than that at around day $30 \mathrm{pp}$ and the size of the cytoplasm was approximately six-fold larger than the size of its nuclei (Fig. 1C). Mitotically active germ cells at the $\mathrm{M}$-phase were also observed after day 100 pp (Fig. 1C, bottom panel, white-arrowhead).

\section{Changes in nuclear size of developing germ cells reflect germline development}

To characterise changes in nuclear sizes of developing prospermatogonia quantitatively, we measured nuclear sizes of each germ cell using the Fiji programme. At around day $10 \mathrm{pp}$, there were two different peaks in the nuclear size distribution of germ cells (Supplementary Fig. 2A). Around day $30 \mathrm{pp}$, nuclear size distribution of germ cells decreased to around 15-20 $\mu^{2}$ (Supplementary Fig. 2A). Between day 8 pp and day 31 pp, there was a significant decrease in nuclear size (linear regression analysis, $P<0.05$, Adjusted R-squared=0.415, Fig. 2A). This significant decrease likely reflects a loss of nuclear volume due to rapid mitotic activity. After day $30 \mathrm{pp}$, nuclear sizes gradually increased as seen in Fig. $1 \mathrm{C}$, and there was a significant increase in median nuclear size (linear regression analysis, $P<0.05$, Adjusted R-squared $=0.435$, Fig. 2B), implying that rapid proliferation had ceased. Between day $40 \mathrm{pp}$ and day $80 \mathrm{pp}$, the peaks of the distributions of each age group shifted towards $30 \mu \mathrm{m}^{2}$ (Supplementary Fig. 2B). After day 100 pp, there were no significant changes in nuclear size (linear regression analysis, $P>0.05$, adjusted R-squared $=-0.036$, Fig. 2C).

\section{Germ cells were significantly condensed in testis cords at day 30 pp that may reflect a phase of rapid proliferation}

We analysed numbers of germ cells within testis cord sections in developing testes to assess changes in cell numbers within testis cords. There was no significant difference in testis cord area until around day $150 \mathrm{pp}$, then the testis cord area significantly increased approximately two-fold at around day $190 \mathrm{pp}$ (Supplementary Fig. 1). From day $10 \mathrm{pp}$ to day $30 \mathrm{pp}$, numbers of germ cells within each testis cord section, 'Germ cell frequencies', significantly increased approximately 3.5-fold (linear regression analysis, $P<0.05$, adjusted R-squared $=0.825$, Fig. $3 \mathrm{~A}$ and B). At day $30 \mathrm{pp}$, the germ cell frequency was significantly higher compared with other ages (Tukey Kramer's HSD, $P<0.05$, Fig. 3A), suggesting that rapid proliferation occurred until day $30 \mathrm{pp}$. The frequency of germ cells was unchanged between day 40 and day 80 
A

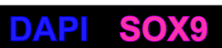

Negative control

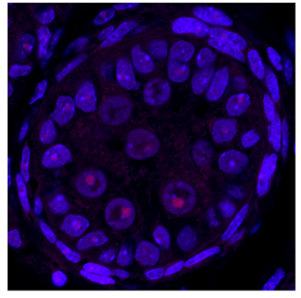

B
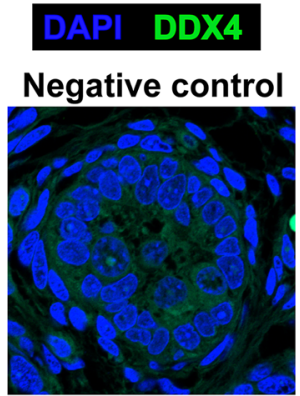

D74 pp

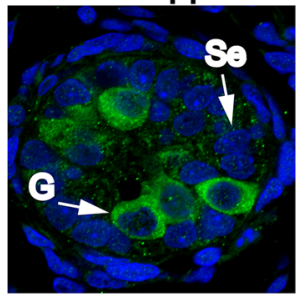

D9 pp

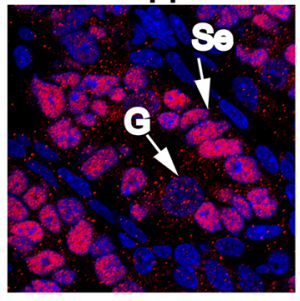

D28 pp

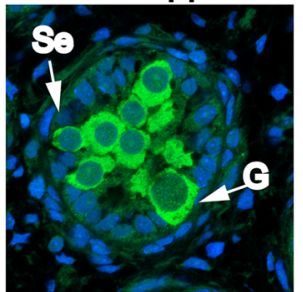

D100 pp

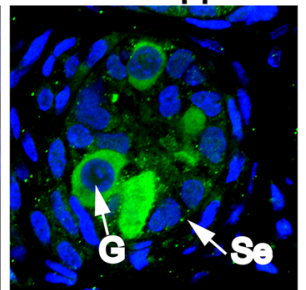

C

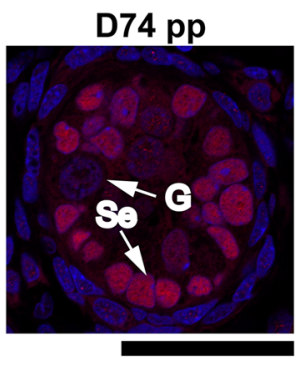

D50 pp

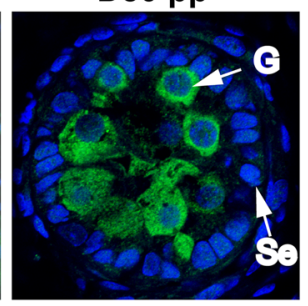

D187 pp

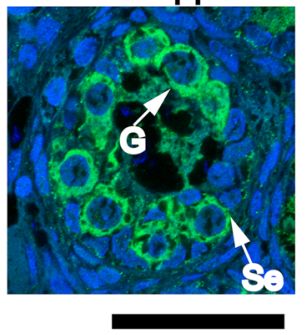

D9 pp

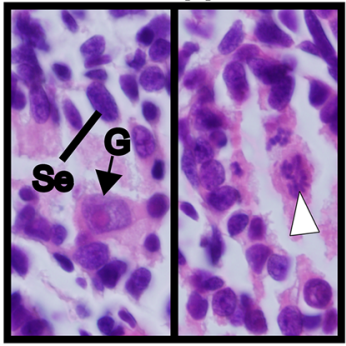

D50 pp

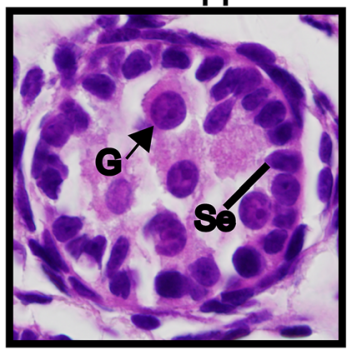

D100 pp

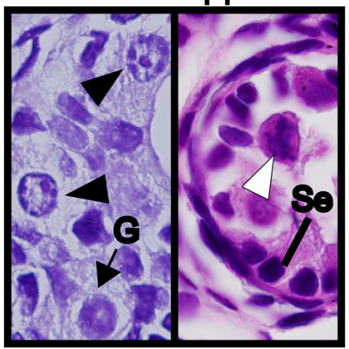

D28 pp

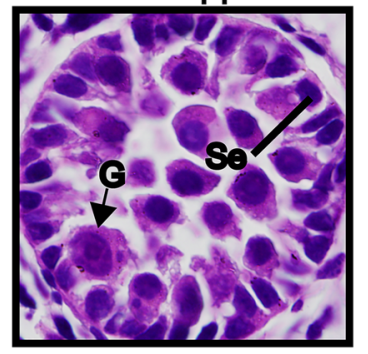

D74 pp

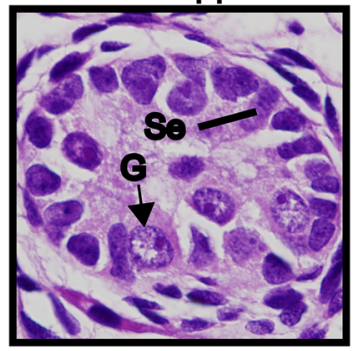

D187 pp

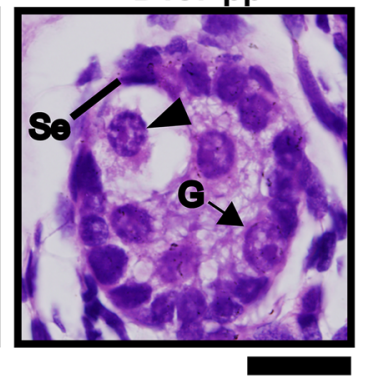

Figure 1 Identification, localisation and DNA methylation dynamics of germ cells. (A) SOX9 marker of Sertoli cells in the developing tammar testes. The Sertoli cells were SOX9-positive and located on the periphery of testis cords throughout all developmental stages. (B) DDX4 marker of pro-spermatogonia in the developing tammar testes. Germ cells were DDX4-positive and centrally located at day 28 pp. At day 50 pp, DDX4positive cells started to move towards the periphery. After day 70 pp, DDX4 positive cells were found at the edge of the testis cord. Scale bars: 50 $\mu \mathrm{m}$. (C) Changes in nuclear architecture of germ cells in the developing testes. At day 9 pp, germ cells had a large nucleus and distinct nucleolus. White arrowhead shows a mitotically active germ cell. At day $28 \mathrm{pp}$, germ cells were centrally located within the testis cords. Black arrow shows a germ cell which has a large nucleus and a distinct ovoid nucleolus. After day 50 pp, germ cells had a large ovoid nucleolus. At day 74 pp, nuclei of germ cells increased in size and were larger than that of day $28 \mathrm{pp}$. After day $100 \mathrm{pp}$, germ cells had developed prominent nucleoli and associated heterochromatin on the nuclear membrane (black arrowhead), undergoing M-phase (white arrowhead). Scale bar: $50 \mu \mathrm{m}$.

pp (Tukey Kramer's HSD, $P>0.05$, Fig. 3A), suggesting that rapid proliferation did not continue after day 40 pp. After day $80 \mathrm{pp}$, there was a significant increase in germ cell frequency (linear regression analysis, $P<0.05$, adjusted $\mathrm{R}$-squared $=0.3243$, Fig. $3 \mathrm{~A}$ and $\mathrm{C}$ ), suggesting that germ cells have resumed mitosis after day $80 \mathrm{pp}$.

\section{Germ cells increase in number before day $30 \mathrm{pp}$ and again after day 100 pp}

To estimate the time that germ cells undergo mitotic arrest and resume mitosis and align these with known phases in mouse pre-spermatogenesis, we assessed germ cell number based on a systematic counting method. From around day $10 \mathrm{pp}$ to around day $30 \mathrm{pp}$, the average number of counted germ cells per unit area (cells $/ \mathrm{mm}^{2}$ ) significantly increased approximately four-fold (Tukey Kramer's HSD, $P<0.05$ and linear regression analysis, $P<0.05$, adjusted R-squared $=0.808$, Fig. $4 \mathrm{~A}$ and $\mathrm{B}$ ). Between day $40 \mathrm{pp}$ to day $80 \mathrm{pp}$, the average numbers of counted germ cells per unit area were almost identical with each other (Tukey Kramer's HSD, $P>0.05$, Fig. $4 \mathrm{~A})$ and there was no significant difference among them (linear regression analysis, $P>0.05$, adjusted R-squared $=-0.022$, Fig. 4C), suggesting that the majority of germ cells up to day $30 \mathrm{pp}$ were $\mathrm{M}$-pro-spermatogonia and began mitotic arrest to becomeT1-pro-spermatogonia after day $30 \mathrm{pp}$. After day $80 \mathrm{pp}$, the average numbers of counted germ cells per unit area significantly increased by 5.5 -fold (linear regression analysis, $P<0.05$, adjusted R-squared $=0.819$, Fig. $4 \mathrm{~A}$ and D), implying that prospermatogonia resumed mitosis after day $80 \mathrm{pp}$. 


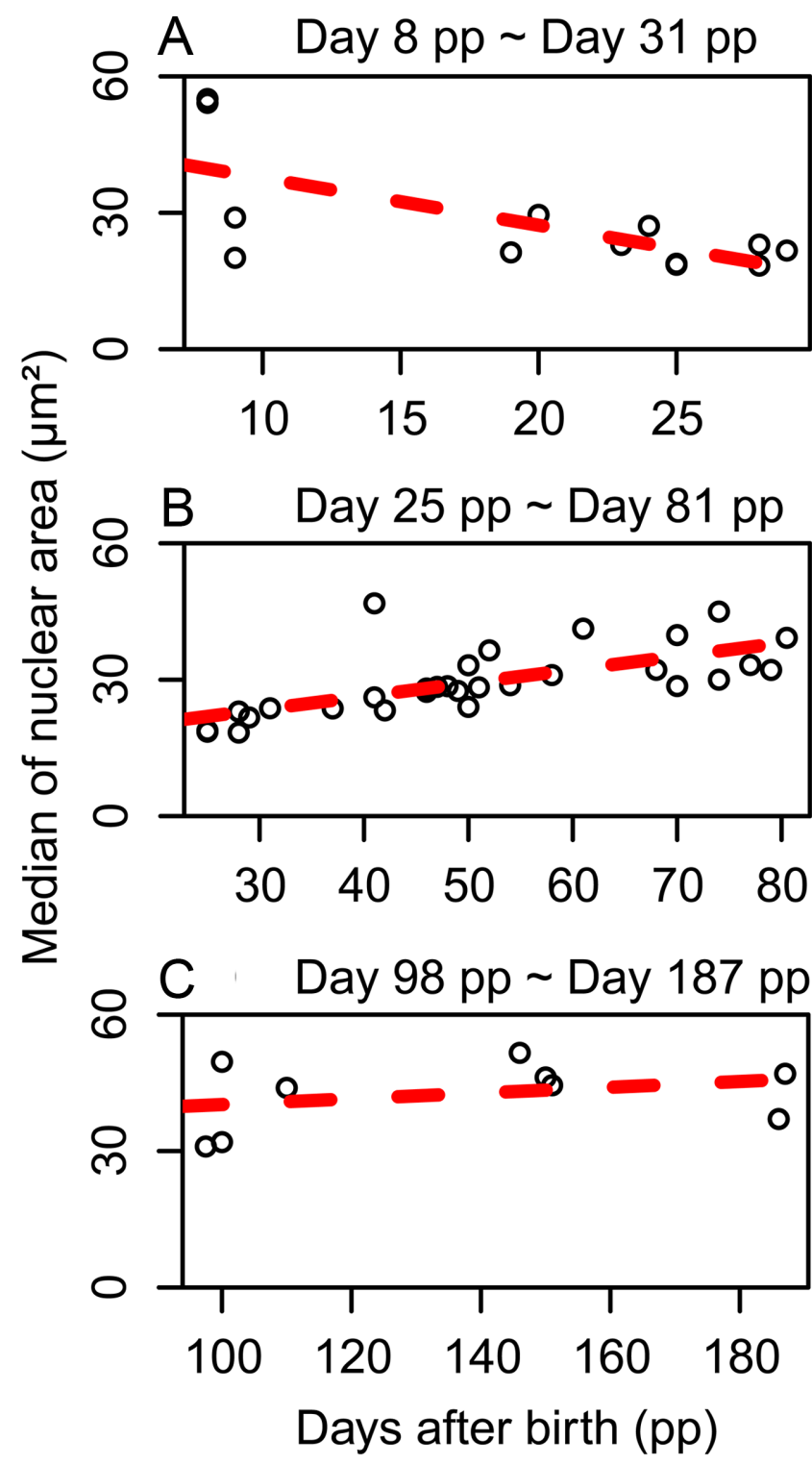

Figure 2 Nuclear sizes are dynamically changed and may reflect germline development. Nuclear size of germ cells was measured throughout the developmental stages. Median values of nuclear size within each animal were calculated and were plotted against their ages. (A) Between around day 8 pp and day 31 pp. The red-dotted line is a linear regression curve fit with adjusted R-squared $=0.415$. (B) Between around day $25 \mathrm{pp}$ and day $81 \mathrm{pp}$. The red-dotted line is a linear regression curve fit with adjusted $R$-squared $=0.435$. (C) Between day $98 \mathrm{pp}$ to day 187 . The red-dotted line is a linear regression curve fit with adjusted $\mathrm{R}$-squared $=-0.036$.

\section{Mitoses decreased from days 25-50 and increased from day 90 pp onwards}

To definitively determine the timing of germ cell proliferation, dual immunofluorescence was performed for the proliferation marker $\mathrm{P}-\mathrm{HH} 3$ (Fig. 5A, red) and the Sertoli cell-specific marker SOX9 (Fig. 5A, green), that allows for differentiation of Sertoli cells from germ
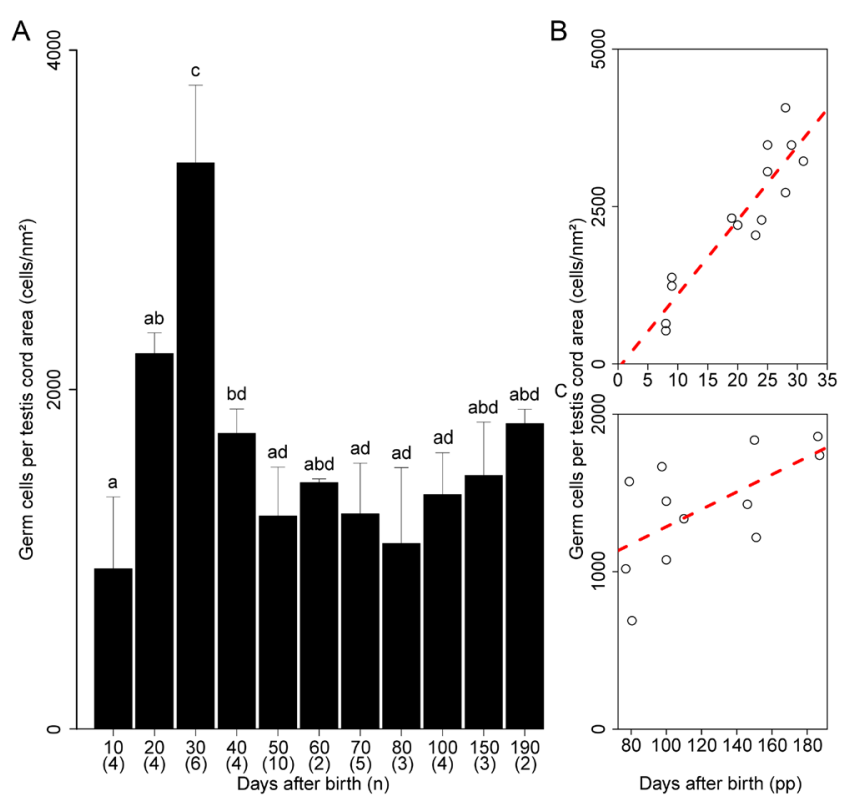

Figure 3 Germ cell frequencies in the developing testes are significantly higher at day $30 \mathrm{pp}$. Numbers of germ cells within each testis cord section were defined as 'Germ cell frequencies'. (A) Germ cell frequencies in the developing testes. Mean \pm SD are shown and sample numbers of each stage are represented as the number in parentheses. Bars labelled with same letters represent values that do not differ significantly by Tukey-Kramer's multiple comparison test at $p<0.05$. (B) Dot-plot and linear regression analysis from day $8 \mathrm{pp}$ to day $31 \mathrm{pp}$. The red-dotted line is a linear regression curve fit with adjusted R-squared $=0.825$. (C) Dot-plot and linear regression analysis from day $77 \mathrm{pp}$ to day $187 \mathrm{pp}$. The red-dotted line is a linear regression curve fit with adjusted $\mathrm{R}$-squared $=0.324$.

cells, and an unbiased automated counting system was employed for quantification. It was not possible to accurately determine the proportion of total germ or Sertoli cells, due to variations in DAPI staining intensity between samples. Therefore, changes in the total proportion of proliferating germ/Sertoli cells was determined (absolute counts are presented in Supplementary Fig. 3). For the timepoints analysed, the absolute number of germ cells are not significantly different when comparing day 20, day 50 and day $70 \mathrm{pp}$ (Fig. 4A), and only minor differences are seen in the absolute number of proliferating Sertoli cells (Supplementary Fig. 3). Therefore, while differences in the total number of Sertoli cells may contribute to changes measured in germ cells below, it is still possible to make inferences on the timing of germ cell arrest during prespermatogenesis. Notably, a significant decrease in germ cell proliferation was observed between day $25 \mathrm{pp}$ and day $50 \mathrm{pp}(P<0.03$, Fig. 5B), and significant increase between day $50 \mathrm{pp}$ and day $90 \mathrm{pp}(P<0.001$ and 0.001 , Fig. 5B). In absolute terms, there was a striking reduction in the number of proliferating germ cells from day $25 \mathrm{pp}$ to day $50 \mathrm{pp}$ (Supplementary Fig. 3), with zero proliferating germ cells identified in two animals from the day 50 pp group, indicating that germ cells at day 50 pp were 

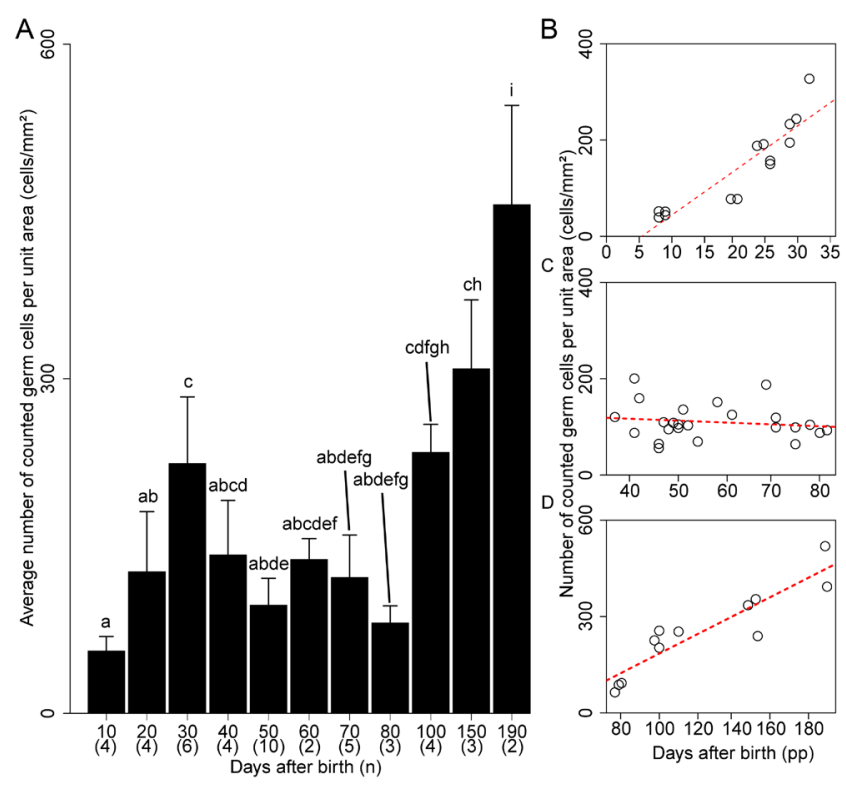

Figure 4 Germ cell numbers increased before day $30 \mathrm{pp}$ and after day $100 \mathrm{pp}$. Germ cells were counted by a random sampling method and total number of germ cells were normalised by the area of the counting frame. (A) Bar graphs of the average numbers of counted germ cells per area (cells $/ \mathrm{mm}^{2}$ ). Mean $\pm \mathrm{SD}$ are shown, and sample numbers of each stage are represented as the number in parentheses. (B) Dot-plot and linear regression analysis from day $8 \mathrm{pp}$ to day 31 pp. The red-dotted line is a linear regression curve fit with adjusted R-squared $=0.808$. (C) Dot-plot and linear regression analysis from day $37 \mathrm{pp}$ to day $81 \mathrm{pp}$. The red-dotted line is a linear regression curve fit with adjusted R-squared $=-0.022$. (D) Dot-plot and linear regression analysis form day 77 to day $187 \mathrm{pp}$. The red-dotted line is a linear regression curve fit with adjusted $\mathrm{R}$-squared $=0.819$.

T1-pro-spermatogonia under mitotic arrest. An increase in the absolute number of proliferating germ cells was observed at day $70 \mathrm{pp}$ and day $90 \mathrm{pp}$. Altogether this data is consistent with analyses shown in Fig. 4, with the addition of a definitive marker of cell proliferation.

\section{Discussion}

Pro-spermatogonia in the tammar undergo rapid proliferation from immediately after birth for about 30 days before entering mitotic arrest, in contrast to that in eutherians that occurs prenatally (Figs 6 and 7). During mitotic arrest, pro-spermatogonia moves to the periphery of testis cords and finally resume mitosis during an extended period of pre-spermatogenesis. We found that the major processes of pre-spermatogenesis, rapid proliferation, mitotic arrest and resumption of mitosis, are similar between the mouse and the tammar wallaby, although the timing relative to birth differs.

Up to day $30 \mathrm{pp}$, pro-spermatogonia undergo rapid proliferation and then re-start mitosis from around day $90 \mathrm{pp}$. At day $80 \mathrm{pp}$, nuclei of tammar
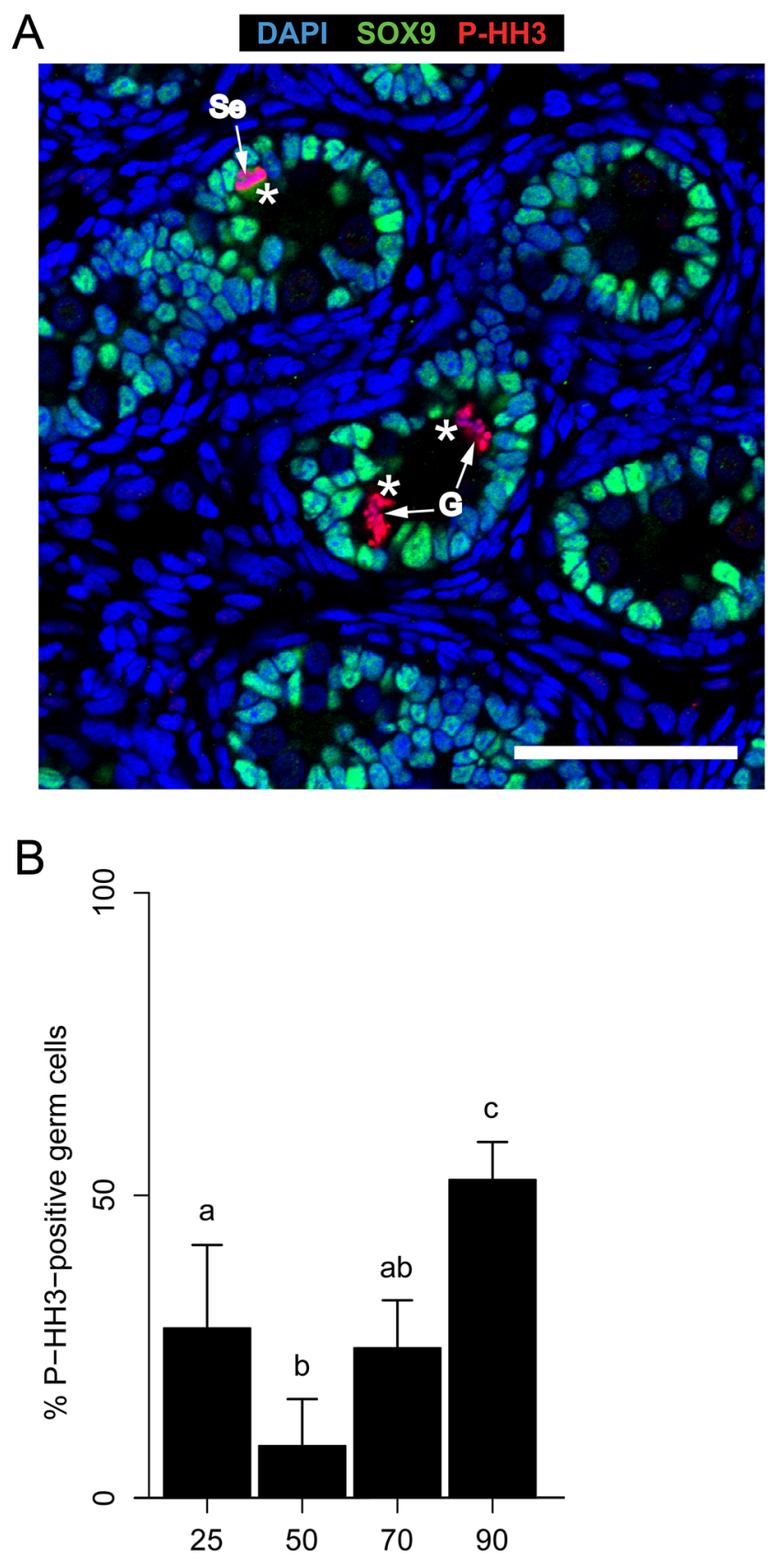

Days after birth (pp)

Figure 5 Germ cells resumed mitotic activity from day $90 \mathrm{pp}$ in the tammar wallaby. (A) Representative immunofluorescence images of wallaby pouch young testis at D90 pp. The section was immunostained for the Sertoli cell marker SOX9 (green) and the proliferation marker P-HH3 (red). Asterisks show P-HH3-positive cells. There are two P-HH3-positive germ cells and one $\mathrm{P}-\mathrm{HH} 3$ / SOX9-positive Sertoli cell in the photo. G, Germ cells; Se, Sertoli cell. (B) Bar graphs of the proportion of $\mathrm{P}-\mathrm{HH} 3$ positive germ cells as a proportion of total proliferating cells in testis cords $(n=5 /$ group, mean +S.D. are shown). Bars labelled with same letters represent values that do not differ significantly by ANOVA with Tukey's multiple comparisons test at $P<0.05$. Scale bar: $50 \mu \mathrm{m}$. 

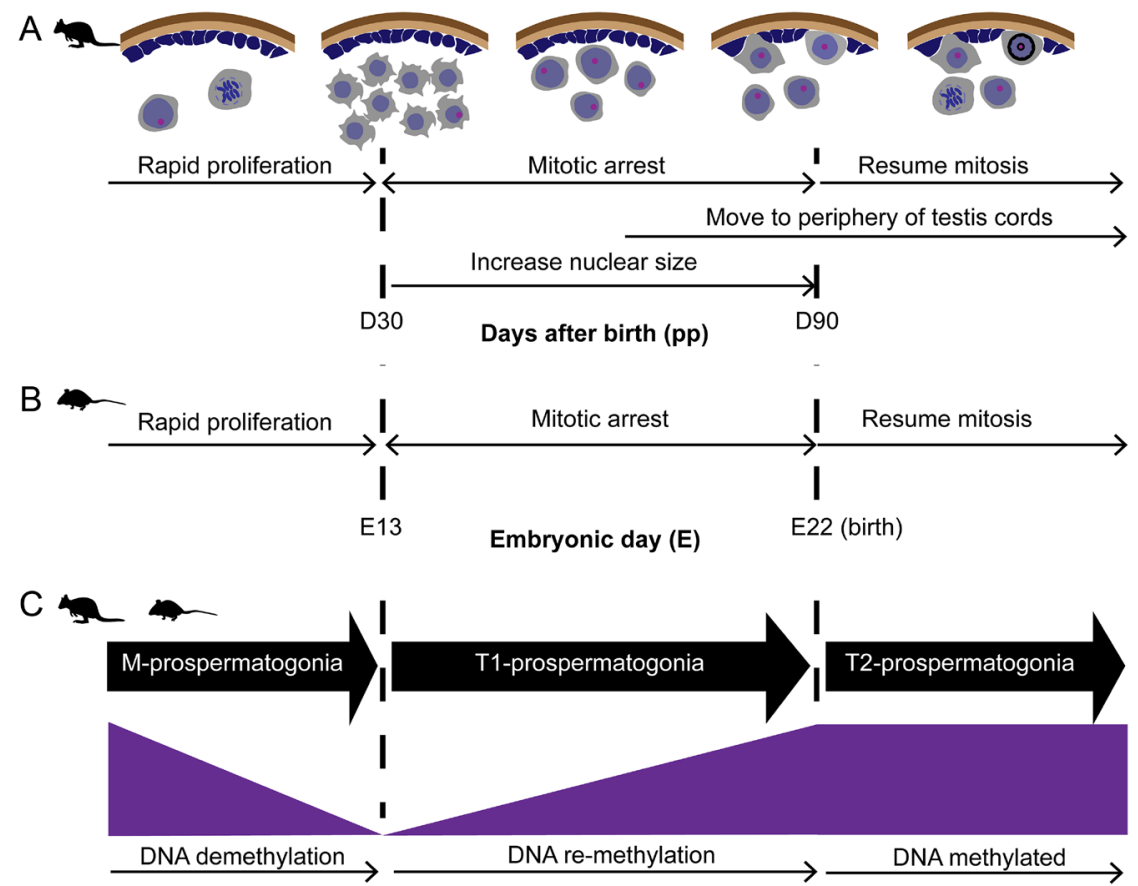

Figure 6 DNA methylation dynamics is highly correlated with pre-spermatogenesis in therian mammals. (A) Changes in the morphology and germ cell location within testis cords during development in the tammar (this study). All processes are represented by arrows with text above. (B) Pre-spermatogenesis in the mouse. All processes are represented by arrows with text above. (C) DNA methylation reprogramming during pre-spermatogenesis in therian mammals. Loss of DNA methylation occurs in M-pro-spermatogonia during rapid-proliferation. DNA demethylation completes when germ cells begin mitotic arrest and become T1-pro-spermatogonia. Re-establishment of DNA methylation completes when the germ cells resume mitosis. DNA methylation information is based on data for the mouse provided in Coffigny et al. (2000), Ernst et al. (2017) and for the tammar (Ishihara et al. 2019).

T1-pro-spermatogonia had significantly larger area than that at day $30 \mathrm{pp}$. This measurement is possible in marsupials because of their long post-natal T1-prospermatogonia phase and mitotic arrest during pre-
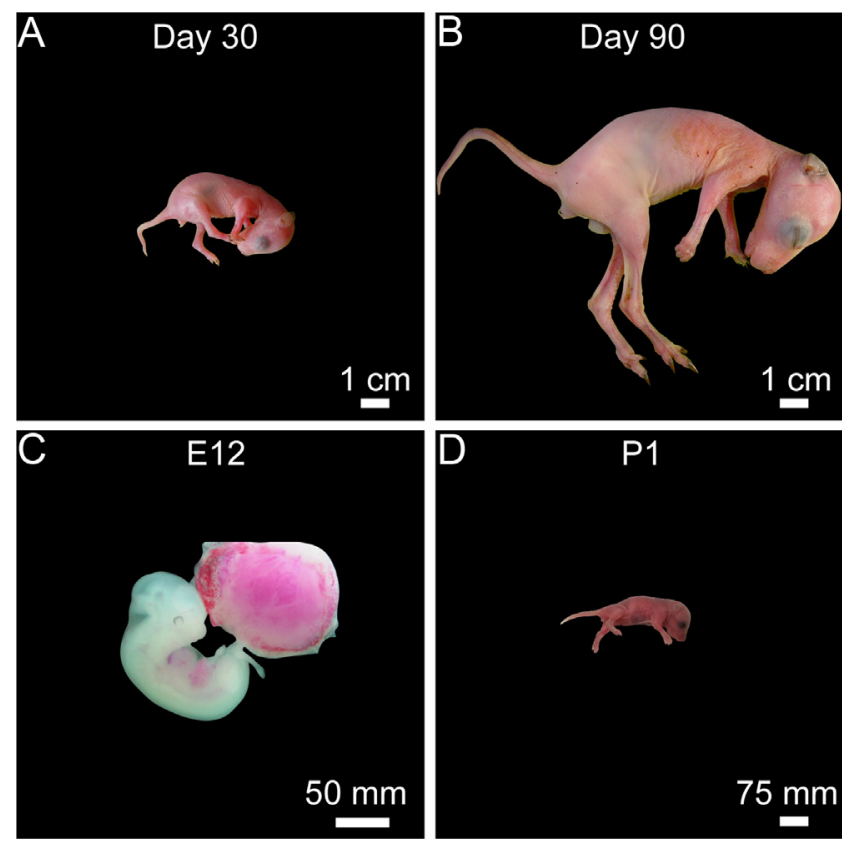

Figure 7 Images of the tammar wallaby PYs and mice. (A) Day $30 \mathrm{pp}$ pouch young (PY). Eyes are closed. The phallus shows no sexual dimorphisms. (B) Day 90 pp PY. Claws have grown. Testicular descent is complete. Eyes are still closed. (C) E12 mouse embryo. Both forelimbs and hindlimbs are still limb buds. Foetus is attached to the placenta. (D) P1 mouse. Eyes are still closed. (A and B) scale bars $1 \mathrm{~cm}$ and (C) scale bar $50 \mathrm{~mm}$ and (D) scale bar $75 \mathrm{~mm}$. spermatogenesis. In mice at days $0-1$ after birth, when most DNA methylation is re-established in the mouse (Coffigny et al. 2000), T1-pro-spermatogonia resume mitosis and the daughter cells are known as T2-prospermatogonia (McCarrey 2013). Nuclei of mouse T2-pro-spermatogonia are larger than that of T1-prospermatogonia (Kluin \& Rooij 1981), suggesting that expanding nuclei during the transitional phase also occurs in eutherian mammals. Germ cells with prominent nucleoli and associated heterochromatin on the nuclear membrane appeared from day $100 \mathrm{pp}$ in the tammar. Heterochromatin is replicated and assembled during mitotic-S phase (Bailis \& Forsburg 2003, Wu et al. 2005, Lu \& Gilbert 2007), and distinct heterochromatin is also detected in T2-pro-spermatogonia in developing human testis (Franke et al. 2004). Constitutive heterochromatin is also re-organised during pre-spermatogenesis in mouse and mouse T2-pro-spermatogonia have established heterochromatin patterns (Yoshioka et al. 2009). Since T2-pro-spermatogonia are mitotically active cells (McCarrey 2013), we concluded that the tammar germ cells that appeared with heterochromatin structures on their nuclear membrane from day 100 pp are T2-prospermatogonia and may be proceeding into mitotic S-phase. Our data clearly showed that the processes of pre-spermatogenesis are conserved between the tammar and eutherians, but in the tammar it all occurred postnatally.

DNA methylation reprogramming during prespermatogenesis is achieved by a global demethylation followed by DNA re-methylation. In the tammar, global DNA demethylation occurs between day $10 \mathrm{pp}$ and day 25 pp (Suzuki et al. 2013, Ishihara et al. 2019) 
and coincides with the rapid proliferation phase of M-pro-spermatogonia, suggesting that loss of DNA methylation could be achieved by DNA replicationdependent passive demethylation occurring in M-prospermatogonia. In eutherians, re-establishment of DNA methylation occurs in germ cells under mitotic arrest (Sasaki \& Matsui 2008). In the tammar, DNA re-methylation occurs after day $30 \mathrm{pp}$, which is also when germ cells start to become mitotically inactive T1-pro-spermatogonia (Ishihara et al. 2019). Re-starting mitosis coincides with the establishment of DNA methylation (Fig. 6). This pattern is also observed in mice (Kafri et al. 1992, Coffigny et al. 2000), suggesting that the male germline development may be influenced by the dynamic wave of DNA methylation reprogramming in therian mammals.

Our results show that pre-spermatogenesis occurs over an extended period of time in the tammar and is associated with the known timing DNA methylation reprogramming in this species. The tammar wallaby has a pattern of DNA methylation reprogramming during early male germline development similar to that of the mouse, but it occurs post-natally instead of prenatally (Ishihara et al. 2019). While the time frames differ, it is clear that the cellular dynamics of pre-spermatogenesis are similar in eutherians and marsupials (Fig. 6), suggesting this process has been conserved through at least 160 million years of evolution (Luo et al. 2011). The cellular dynamics of male germ cells occurs at the same time as DNA methylation dynamics changes in the tammar, suggesting that the global wave of DNA methylation reprogramming, which is also conserved over $160 \mathrm{Mya}$, is tightly correlated with male germline development in therian mammals. This prolonged process of pre-spermatogenesis in the tammar provides a useful model for further studies on the importance of epigenetic reprogramming for germline development.

\section{Supplementary materials}

This is linked to the online version of the paper at https://doi. org/10.1530/REP-20-0634.

\section{Declaration of interest}

The authors declare that there is no conflict of interest that could be perceived as prejudicing the impartiality of the research reported.

\section{Funding}

This work was supported by the Melbourne Research Scholarship from the University of Melbourne and the Australian Research Council.

\section{Author contribution statement}

Conceived and designed the experiments: TI, M B R. Performed the experiments: T I, G A T. Analysed the data: T I, O W G, G A T, M B R. Wrote the paper: T I, O W G, G A T, M B R.

\section{Acknowledgements}

The authors thank members of the wallaby research group for assistance with the animals. The authors thank Professor Geoff Shaw (University of Melbourne) for the images of the tammar pouch young. The authors thank Arata Wakimoto and Shinnosuke Yasugaki (University of Tsukuba) for providing images of the embryo and newborn mouse. The authors thank the Melbourne University Biological Optical Microscopy Platform (BOMP) for assistance with the Confocal microscopy.

\section{References}

Arney KL \& Fisher AG 2004 Epigenetic aspects of differentiation. Journal of Cell Science 117 4355-4363. (https://doi.org/10.1242/jcs.01390)

Bailis JM \& Forsburg SL 2003 It's all in the timing: linking S phase to chromatin structure and chromosome dynamics. Cell Cycle 2 303-306. (https://doi.org/10.4161/cc.2.4.434)

Bartolomei MS \& Ferguson-Smith AC 2011 Mammalian genomic imprinting. Cold Spring Harbor Perspectives in Biology 3 a002592. (https://doi.org/10.1101/cshperspect.a002592)

Coffigny H, Bourgeois C, Ricoul M, Bernardino J, Vilain A, Niveleau A, Malfoy B \& Dutrillaux B 2000 Alterations of DNA methylation patterns in germ cells and Sertoli cells from developing mouse testis. Cytogenetic and Genome Research 87 175-181. (https://doi.org/10.1159/000015460)

Culty M 2009 Gonocytes, the forgotten cells of the germ cell lineage. Birth Defects Research: Part C, Embryo Today 87 1-26. (https://doi. org/10.1002/bdrc.20142)

Ernst C, Odom DT \& Kutter C 2017 The emergence of piRNAs against transposon invasion to preserve mammalian genome integrity. Nature Communications 8 1411. (https://doi.org/10.1038/s41467-017-01049-7)

Franke FE, Pauls K, Rey R, Marks A, Bergmann M \& Steger K 2004 Differentiation markers of Sertoli cells and germ cells in fetal and early postnatal human testis. Anatomy and Embryology 209 169-177. (https:// doi.org/10.1007/s00429-004-0434-x)

Fukushima S, Terasaki M, Sakata K, Miyagi N, Kato S, Sugita Y \& Shigemori M 2009 Sensitivity and usefulness of anti-phosphohistone-H3 antibody immunostaining for counting mitotic figures in meningioma cases. Brain Tumor Pathology 26 51-57. (https://doi.org/10.1007/ s10014-009-0249-9)

Hackett JA, Sengupta R, Zylicz JJ, Murakami K, Lee C, Down TA \& Surani MA 2013 Germline DNA demethylation dynamics and imprint erasure through 5-hydroxymethylcytosine. Science $339 \quad 448-452$. (https://doi.org/10.1126/science.1229277)

Hargan-Calvopina J, Taylor S, Cook H, Hu Z, Lee SA, Yen MR, Chiang YS, Chen PY \& Clark AT 2016 Stage-specific demethylation in primordial germ cells safeguards against precocious differentiation. Developmental Cell 39 75-86. (https://doi.org/10.1016/j.devcel.2016.07.019)

Ishihara T, Hickford D, Shaw G, Pask AJ \& Renfree MB 2019 DNA methylation dynamics in the germline of the marsupial tammar wallaby, Macropus eugenii. DNA Research 26 85-94. (https://doi.org/10.1093/ dnares/dsy040)

Kafri T, Ariel M, Brandeis M, Shemer R, Urven L, McCarrey J, Cedar H \& Razin A 1992 Developmental pattern of gene-specific DNA methylation in the mouse embryo and germ line. Genes and Development 6 705-714. (https://doi.org/10.1101/gad.6.5.705)

Kawasaki Y, Lee J, Matsuzawa A, Kohda T, Kaneko-Ishino T \& Ishino F 2014 Active DNA demethylation is required for complete imprint erasure in primordial germ cells. Scientific Reports 4 3658. (https://doi. org/10.1038/srep03658) 
Kluin PM \& Rooij DG 1981 A comparison between the morphology and cell kinetics of gonocytes and adult type undifferentiated spermatogonia in the mouse. International Journal of Andrology 4 475-493. (https://doi. org/10.1111/j.1365-2605.1981.tb00732.x)

Kocer A, Reichmann J, Best D \& Adams IR 2009 Germ cell sex determination in mammals. Molecular Human Reproduction 15 205-213. (https://doi org/10.1093/molehr/gap008)

Lu J \& Gilbert DM 2007 Proliferation-dependent and cell cycle-regulated transcription of mouse pericentric heterochromatin. Journal of Cell Biology 179 411-421. (https://doi.org/10.1083/jcb.200706176)

Luo ZX, Yuan CX, Meng QJ \& Ji Q 2011 A Jurassic eutherian mammal and divergence of marsupials and placentals. Nature 476 442-445. (https:// doi.org/10.1038/nature10291)

Matsui Y \& Mochizuki K 2014 A current view of the epigenome in mouse primordial germ cells. Molecular Reproduction and Development 81 160-170. (https://doi.org/10.1002/mrd.22214)

McCarrey JR 2013 Toward a more precise and informative nomenclature describing fetal and neonatal male germ cells in rodents. Biology of Reproduction 89 47. (https://doi.org/10.1095/biolreprod.113.110502)

McLaren A 1992 Development of primordial germ cells in the mouse. Andrologia 24 243-247. (https://doi.org/10.1111/j.1439-0272.1992. tb02647.x)

McLaren A 2001 Mammalian germ cells: birth, sex, and immortality. Cell Structure and Function 26 119-122. (https://doi.org/10.1247/csf.26.119)

Poole WE, Simms NG, Wood JT \& Lubulwa M 1991 Tables for Age Determination of the Kangaroo Island Wallaby (Tammar) Macropus eugenii. CSIRO. (https://doi.org/10.4225/08/58a5e9b2bf231)

Pui HP \& Saga Y 2018 NANOS2 acts as an intrinsic regulator of gonocytesto-spermatogonia transition in the murine testes. Mechanisms of Development 149 27-40. (https://doi.org/10.1016/j.mod.2018.01.001)

Sasaki H \& Matsui Y 2008 Epigenetic events in mammalian germ-cell development: reprogramming and beyond. Nature Reviews: Genetics 9 129-140. (https://doi.org/10.1038/nrg2295)
Suzuki A \& Saga Y 2008 Nanos2 suppresses meiosis and promotes male germ cell differentiation. Genes and Development 22 430-435. (https:// doi.org/10.1101/gad.1612708)

Suzuki S, Shaw G \& Renfree MB 2013 Postnatal epigenetic reprogramming in the germline of a marsupial, the tammar wallaby. Epigenetics and Chromatin 6 14. (https://doi.org/10.1186/1756-8935-6-14)

Wartenberg H 1978 Human testicular development and the role of the mesonephros in the origin of a dual Sertoli cell system. Andrologia 10 1-21. (https://doi.org/10.1111/j.1439-0272.1978.tb01306.x)

Western PS, Miles DC, van den Bergen JA, Burton M \& Sinclair AH 2008 Dynamic regulation of mitotic arrest in fetal Male germ cells. Stem Cells 26 339-347. (https://doi.org/10.1634/stemcells.2007-0622)

Wu R, Terry AV, Singh PB \& Gilbert DM 2005 Differential subnuclear localization and replication timing of histone $\mathrm{H} 3$ lysine 9 methylation states. Molecular Biology of the Cell 16 2872-2881. (https://doi. org/10.1091/mbc.e04-11-0997)

Yamaguchi S, Hong K, Liu R, Shen L, Inoue A, Diep D, Zhang K \& Zhang Y 2012 Tet1 controls meiosis by regulating meiotic gene expression. Nature 492 443-447. (https://doi.org/10.1038/nature11709)

Yoshioka H, McCarrey JR \& Yamazaki Y 2009 Dynamic nuclear organization of constitutive heterochromatin during fetal male germ cell development in mice. Biology of Reproduction 80 804-812. (https://doi. org/10.1095/biolreprod.108.072603)

Received 28 November 2020

First decision 22 December 2020

Revised manuscript received 16 January 2021

Accepted 21 January 2021 